\title{
INFLUÊNCIA DE VARIÁVEIS CLIMÁTICAS E HIDRÁULICAS NO DESEMPENHO DA IRRIGAÇÃO DE UM PIVÔ CENTRAL NO OESTE BAIANO ${ }^{1}$
}

\author{
JACQUES M. PINTO ${ }^{2}$, CÍCERO L. DA SILVA ${ }^{3}$, CARLOS A. DA S. OLIVEIRA ${ }^{4}$
}

\begin{abstract}
RESUMO: Este trabalho foi conduzido na Fazenda Moreno, localizada no município de Barreiras, oeste baiano, com o objetivo de avaliar o desempenho de um pivô central, em função de variáveis climáticas e hidráulicas ligadas à eficiência de irrigação, em três períodos do ano e duas velocidades de rotação da linha lateral do equipamento. Os três períodos de coletas dos dados foram 12 e 18-5-2002 (primeira época), 27 e 28-7-2002 (segunda época) e 28 e 29-9-2002 (terceira época), respectivamente, para 100 e $50 \%$ da velocidade máxima de deslocamento do pivô. Os resultados foram analisados em blocos casualizados para o fator velocidade de deslocamento do pivô, com o fator época do ano em subparcela. O sistema avaliado apresentou pressão no final da linha lateral, menor que a recomendada e, como conseqüência, a lâmina de água aplicada nesse ponto ficou abaixo da média. As eficiências de irrigação (Ei) foram menores do que o recomendado pela literatura como aceitáveis $(80 \%)$. As maiores lâminas coletadas têm sua frequiência acumulada reduzida com o avanço da estação seca ao longo do ano. A umidade relativa do ar e especialmente a velocidade do vento influenciaram significativamente no valor da eficiência de aplicação.
\end{abstract}

PALAVRAS-CHAVE: coeficiente de uniformidade de Christiansen, eficiência de distribuição, eficiência de aplicação.

\section{CLIMATIC AND HIDRAULIC VARIABLES INFLUENCE ON CENTER PIVOT PERFORMANCE IN THE WEST OF BAHIA STATE}

\begin{abstract}
This work was carried out at Moreno's farm, located in Barreiras, west of Bahia State, Brazil with the objective to evaluate the performance of a center pivot of irrigation, regarding the irrigation efficiency due to climatic and hydraulic variable during three periods of the year and under two lateral line rotation speeds. The three-field test was conducted, during the year 2002, in May 12 and 18; July 27 and 28; and September 28 and 29; the center pivot was operated with 100 and $50 \%$ of maximum rotation speed. The results were analyzed considering a randomized complete block design for lateral rotation speed factor, and with time factor as a split plot on lateral rotation speed. Results showed that the operating pressure at the lateral end was lower than the recommended one allowing an irrigation water depth below the average at that place. Values of irrigation efficiency were smaller than the ones recommended in the literature $(80 \%)$. The irrigation depth of water was reduced from the first to the third time of evaluation, due to climatic changes. Relative humidity and specially wind speed had more influence on the application efficiency.
\end{abstract}

KEYWORDS: Christiansen uniformity coefficient, distribution efficiency, application efficiency.

\footnotetext{
${ }^{1}$ Extraído da dissertação de mestrado do primeiro autor.

${ }^{2}$ Eng ${ }^{\underline{0}}$ Agrônomo, M.Sc., CODEVASF/2ํㅡㄴ NBA, Barreiras - BA, jacques.pinto@ bol.com.br.

${ }^{3}$ Prof. Adjunto, Doutor, FAV, UnB, Caixa Postal 04508, Brasília - DF, cicero@unb.br.

${ }^{4}$ Prof. Titular, Ph. D., FAV, UnB, Caixa Postal 04508, Brasília - DF.

Recebido pelo Conselho Editorial em: 20-4-2004

Aprovado pelo Conselho Editorial em: 7-2-2006
} 


\section{INTRODUÇÃO}

De acordo com CHRISTOFIDIS (2002), a superfície agrícola mundial, submetida à colheita no ano de 2000, correspondeu a aproximadamente 1,5 bilhão de hectares, dos quais cerca de 275 milhões (18\%) foram irrigados. A superfície produtiva agrícola sob sequeiro, em torno de 1,225 bilhão de ha, foi responsável por $58 \%$ do total colhido, enquanto a superfície agrícola irrigada respondeu por $42 \%$ do total colhido em 2000. Segundo o mesmo autor, no Brasil, em 2001, a área irrigada era de 3.149.217 ha, sendo que, dos métodos atualmente utilizados no País, a aspersão via pivô central ocupa a maior área, com 651.548 ha.

Na irrigação por aspersão, a água é aplicada ao solo sob a forma de chuva artificial. Isso ocorre devido ao fracionamento do jato de água, em grande número de gotas que se dispersam no ar e caem sobre a superfície do solo ou do dossel vegetativo. Destacam-se nesse grupo os sistemas convencional, autopropelido, pivô central e linear (RAMOS \& MANTOVANI et al., 1994).

Os sistemas de irrigação por aspersão mecanizada surgiram com o intuito de obter maior eficiência no uso de água e redução de mão-de-obra. Atualmente, o pivô central é o sistema mais automatizado que existe, e surgiu nos Estados Unidos da América em 1952. É constituído de uma linha lateral de aspersores montados sobre armações com rodas, denominadas de torres, tendo uma das extremidades fixada em uma estrutura piramidal (ponto-pivô), enquanto as outras torres se movem continuamente em torno desse ponto durante a aplicação de água (RAMOS \& MANTOVANI et al., 1994). No Brasil, esse sistema tem sido utilizado principalmente para irrigação de cereais, mas, nos últimos anos, tem havido crescente aumento da sua utilização em fruticultura e pastagem (FOLEGATTI et al., 1998).

O manejo racional da irrigação via pivô central requer, além do conhecimento de parâmetros climáticos, de características das culturas, dos solos e dos recursos hídricos, o conhecimento da distribuição e quantidade de água aplicada e das eficiências de aplicação e distribuição (FURUKAWA et al., 1994).

Trabalhando com o modelo de Walker, que relaciona a eficiência de distribuição (Ed) em função do coeficiente de variação e área deficientemente irrigada e com velocidade de rotação do pivô de 20; 40 e 60\% da máxima, RESENDE et al. (1996) obtiveram valores de 37; 98,3 e 100\%, respectivamente, para Ed. ASSIS \& CASTRO (1993), trabalhando com o pivô central a 80 e $100 \%$ de sua velocidade máxima e com a metodologia de Merrian e Keller (KELLER \& BLIESNER, 1990), para o cálculo da Ed, obtiveram valores de 70,8 e 81,3\%, respectivamente. Em todos esses trabalhos mencionados, os coeficientes de uniformidade estiveram acima do considerado satisfatório pela literatura, ou seja, $80 \%$ (BERNARDO, 1995; KELLER \& BLIESNER, 1990). Porém, a eficiência de irrigação conjugada, resultante do produto da eficiência de aplicação pela eficiência de distribuição e eficiência de condução, não foi calculada.

A região oeste da Bahia está situada à margem esquerda do Rio São Francisco, banhada pelas bacias dos rios Grande, Carinhanha e Corrente; conta com 39 municípios abrangendo superfície total de 162 mil km² e população de 800 mil habitantes, equivalendo a $28,5 \%$ do território e $6,2 \%$ da população da Bahia, sendo sua economia predominantemente agropecuária. Nas duas últimas décadas, o cultivo de grãos, juntamente com a pecuária, definiram nova dinâmica na economia que proporcionou o desenvolvimento da microrregião de Barreiras. Essa região possui bacias hidrográficas formadas por 29 rios perenes, solos planos, profundos e de boa drenagem. Possui variação climática de úmido a subúmido e de seco a subúmido. As temperaturas médias máximas e mínimas anuais variam entre 34 e $14{ }^{\circ} \mathrm{C}$, respectivamente. A pluviosidade situa-se entre 700 e $1.800 \mathrm{~mm}$ por ano, concentrada em $83 \%$ do período chuvoso, de outubro a abril, e a luminosidade em torno de 3.000 horas por ano. A partir de 1984/85, foram implantados os primeiros projetos de irrigação sob pivô central, 
principalmente nos municípios de São Desidério e Barreiras. Em 1993, a área irrigada na região atingia 39.104 ha com 376 pivôs centrais instalados (268 na bacia do Rio Grande e 108 na bacia do Rio Corrente). A área irrigada no ano 2000 era de aproximadamente 75 mil ha, sendo 66 mil ha via pivô central, com área média em torno de 100 ha por equipamento (BARREIRAS, 2000).

Diversos trabalhos têm sido feitos no Brasil para estudar o comportamento da irrigação (ASSIS \& CASTRO, 1993; CEMIG, 1993; FURUKAWA et al., 1993; REZENDE et al., 1993; REZENDE et al., 1996; CAINELLI et al., 1997; FOLEGATTI et al., 1998; HEINEMANN et al., 1998; KLAR et al., 2001), mas, na região oeste da Bahia que tem área expressiva irrigada por pivô central, ainda não foram feitos estudos necessários para identificar quais os principais problemas e soluções envolvendo a melhora da eficiência de irrigação por esse sistema.

Este trabalho teve como objetivo avaliar o desempenho da irrigação de um pivô central, em termos da eficiência de aplicação e distribuição, em três épocas do ano, com condições climáticas diferentes e com duas velocidades de rotação do equipamento.

\section{MATERIAL E MÉTODOS}

O presente trabalho foi conduzido na Fazenda Moreno, município de Barreiras, oeste da Bahia, cujo ponto central apresenta latitude de $11^{\circ} 45^{\prime} 01^{\prime \prime}$ sul, longitude de $45^{\circ} 43^{\prime} 32^{\prime}$ ' oeste e altitude média de $750 \mathrm{~m}$. A cobertura vegetal local é predominantemente do tipo Campo Limpo. Os solos são do tipo Latossolo Vermelho-Amarelo de textura média a arenosa e o relevo é bastante plano. Na Fazenda Moreno, a média anual da precipitação e da temperatura é, respectivamente, $1.100 \mathrm{~mm}$ e $23{ }^{\circ} \mathrm{C}$.

O pivô central testado era composto por uma linha lateral medindo 503,9 m, com diâmetro interno de $168 \mathrm{~mm}$, projetado para operar com pressão de $535 \mathrm{kPa}$ na entrada do pivô e $168 \mathrm{kPa}$ no final da linha lateral; equipado com emissores em pendural, a 1,8 m do solo e espaçados de 3,9 m entre si, montados com regulador de pressão somente a partir do $42^{\circ}$ emissor de um total de 127 . O conjunto motobomba era composto por um motor elétrico de $73,6 \mathrm{~kW}$ a $1.750 \mathrm{rpm}$ e bomba centrífuga capaz de fornecer vazão de $326,73 \mathrm{~m}^{3} \mathrm{~h}^{-1}$ para altura manométrica total de $618 \mathrm{kPa}$. A capacidade nominal de lâmina do equipamento é de $8,5 \mathrm{~mm}$ com tempo de rotação de $21 \mathrm{~h}$. Na velocidade máxima, com tempo de rotação de $8,56 \mathrm{~h}$, a lâmina aplicada é de $3,47 \mathrm{~mm}$.

Além das eficiências de aplicação e distribuição, no intuito de verificar as condições hidráulicas do pivô, foi medida a pressão de operação nos bocais do $1^{\circ}$, do $2^{\circ}$, do $89^{\circ}$, do $124^{\circ}$ e do $125^{\circ}$ emissor ao longo do equipamento. A eficiência de distribuição (Ed) foi calculada de acordo com KELLER \& BLIESNER (1990), fazendo uso do CUC e da área adequadamente irrigada (AAI), a qual, para este trabalho, foi fixada em $80 \%$ e, de acordo com os mesmos autores, que apresentam para Ed a expressão:

$$
\mathrm{Ed}=\left[100+\left(606-24,9 \mathrm{AAI}+0,349 \mathrm{AAI}^{2}-0,00186 \mathrm{AAI}^{3}\right)(1-\mathrm{CUC} / 100)\right]
$$

em que,

CUC - coeficiente de uniformidade de Christiansen, em percentagem.

Adotando-se a AAI de 80\%, conforme KELLER \& BLIESNER (1990), a eq.(1) fica:

$\mathrm{Ed}=100-104,7(1-\mathrm{CUC} / 100)$

Para calcular o CUC, utilizou-se da metodologia proposta por BERNARDO (1995):

$\mathrm{CUC}=100\left\{1-\left[\left(\sum \mid \mathrm{Z}_{\mathrm{S}}-\mathrm{L}_{\mathrm{MP}} \mathrm{l}\right) /\left(\mathrm{nL}_{\mathrm{MP}}\right)\right]\right\}$

em que, $\mathrm{L}_{\mathrm{MP}}$ é a lâmina média ponderada das lâminas coletadas e dada por:

$$
\mathrm{L}_{\mathrm{MP}}=\Sigma\left(\mathrm{SZ}_{\mathrm{S}}\right) / \Sigma \mathrm{S}
$$


em que,

$\mathrm{S}$ - número de ordem do coletor na linha radial de coletores, contado a partir do centro do pivô;

n - número de observações, e

$\mathrm{Z}_{\mathrm{S}}$ - lâmina coletada no coletor de número de ordem $\mathrm{S}$.

A eficiência de aplicação de água (Ea) foi obtida pela relação entre a lâmina média coletada e a lâmina média emitida pelos emissores avaliados. O primeiro emissor avaliado foi o localizado na metade do primeiro terço da linha lateral, o segundo na metade do segundo terço e o terceiro na metade do último terço.

Para caracterizar as condições ambientais, usou-se um termômetro com resolução de $0,1{ }^{\circ} \mathrm{C}$, um anemômetro com velocidade inercial de $0,3 \mathrm{~m} \mathrm{~s}^{-1}$ e um higrômetro com resolução de $1 \%$, todos portáteis.

A eficiência da irrigação (Ei) foi obtida pelo produto das três eficiências: eficiência de distribuição, eficiência de aplicação e eficiência de condução, sendo essa última considerada igual a 1 (um), pois o equipamento não apresentava nenhum vazamento no sistema de condução da água.

Os testes foram realizados em 12 e 18-5-2002 (primeira época), 27 e 28-7-2002 (segunda época) e 28 e 29-9-2002 (terceira época). O primeiro dia para $100 \%$ da velocidade máxima de deslocamento do pivô e o segundo dia para $50 \%$ da velocidade. As datas foram escolhidas para determinar o desempenho do sistema de irrigação no início, meio e fim do período seco. Ressalta-se que, no início do período seco (primeira época), as variáveis climáticas temperatura e umidade relativa do ar foram maiores do que as respectivas variáveis da segunda e terceira épocas, enquanto a velocidade do vento foi menor. Os testes foram conduzidos com o auxílio de 512 coletores, espaçados de 3,9 m entre si, ao longo de quatro raios, dispostos em forma de cruz, com o centro da cruz coincidindo com o centro do pivô.

O delineamento experimental utilizado foi o de blocos completos casualizados para o fator velocidade na parcela e o fator época em subparcela. Os quatro raios de amostragem ao longo do pivô constituíram as repetições.

\section{RESULTADOS E DISCUSSÃO}

As lâminas médias para $100 \%$ da velocidade de deslocamento foram 2,75;2,45 e 2,32 mm, para a primeira, segunda e terceira épocas, respectivamente (Figura 1), valores esses abaixo da média de $3,47 \mathrm{~mm}$, conforme informado pelo fabricante. Para a velocidade de $50 \%$ da capacidade do equipamento, as lâminas médias foram 6,68; 5,10 e 4,95 mm. Os perfis médios de distribuição de água ao longo do pivô permitem visualizar melhor as conseqüências da deficiência de pressão nos emissores e a respectiva variação nas lâminas de água aplicadas. Do início até aproximadamente $170 \mathrm{~m}$ do centro do pivô, há grande variação na lâmina aplicada, causada provavelmente pela ausência de reguladores de pressão. Em geral, até $340 \mathrm{~m}$ do centro do pivô, a lâmina aplicada é maior que a lâmina média, exceto na faixa que vai de 60 a $90 \mathrm{~m}$ do centro do pivô, que pode ser causada pelo uso de bocais inadequados para aquela região da linha lateral, porém essa faixa representa apenas 1,8\% da área irrigada. Todavia, o mesmo não pode ser dito dos últimos $164 \mathrm{~m}$, em que se observam lâminas abaixo da média e representam $45,5 \%$ da área irrigada. 

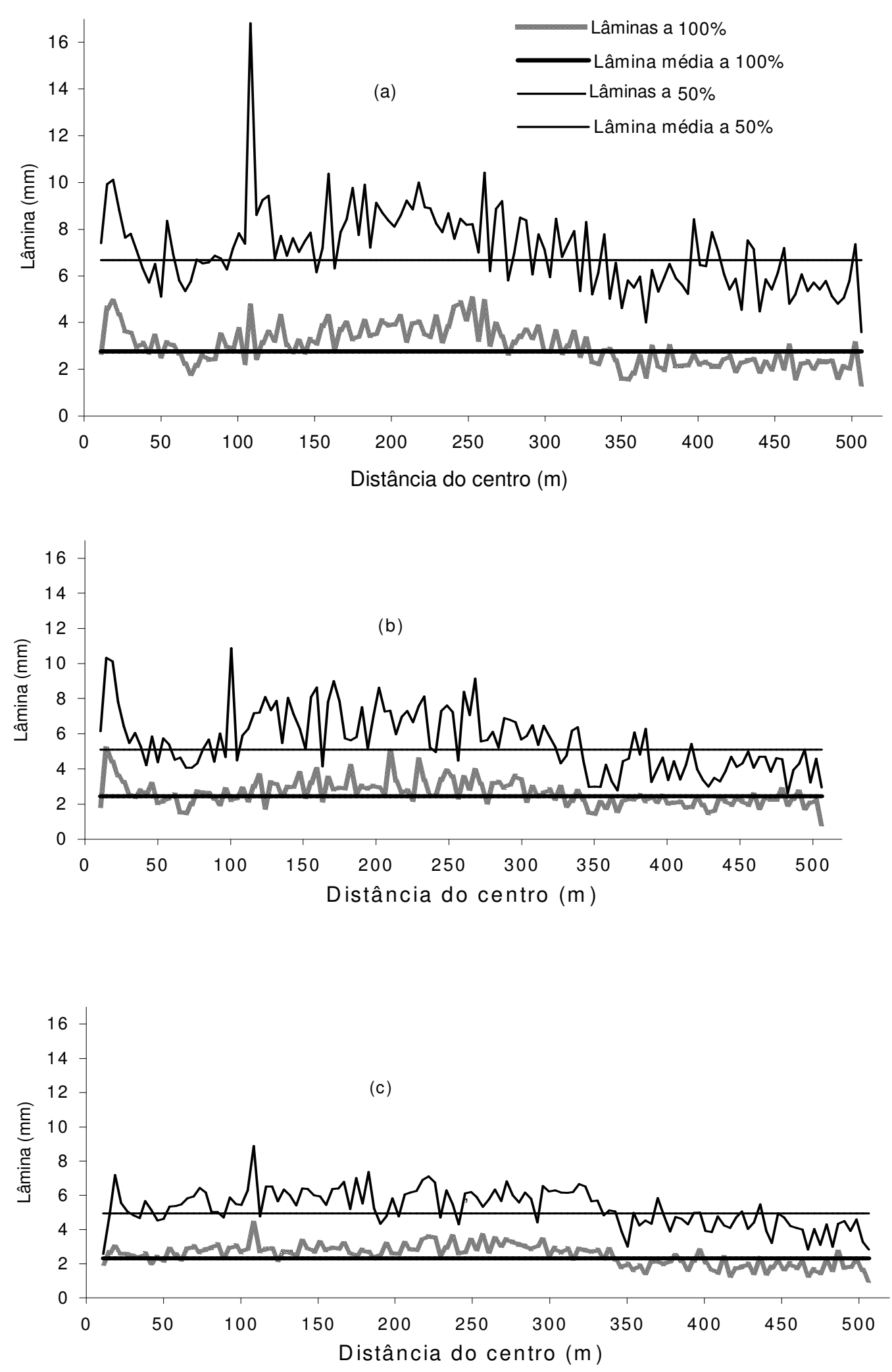

FIGURA 1. Comportamento da variável lâmina de água aplicada ao longo do pivô central a 50 e $100 \%$ da velocidade máxima de deslocamento do pivô. (a) primeira época (12 e 18-5-2002); (b) segunda época (27 e 28-7-2002), e (c) terceira época (28 e 29-9-2002). 
Com relação às pressões observadas ao longo do pivô (Tabela 1), verifica-se que, quando comparadas com a pressão de projeto de $168 \mathrm{kPa}$, houve deficiência a partir do $89^{\mathrm{o}}$ difusor. As pressões observadas nos manômetros de saída da bomba e no tubo de elevação do pivô central apresentaram valores próximos aos mencionados pelo fabricante. A diferença de pressões entre o tubo de elevação e os dois primeiros emissores $(535 \mathrm{kPa}-196 \mathrm{kPa})$ deve-se, principalmente, às perdas de carga que acontecem nesses emissores, devido às dimensões reduzidas de seus bocais $(2 \mathrm{~mm})$.

TABELA 1. Distância e número de ordem a partir do centro e pressão nos emissores ao longo da linha lateral do pivô.

\begin{tabular}{ccc}
\hline Distância do Centro $(\mathrm{m})$ & Número de Ordem do Emissor & Pressão Medida $(\mathrm{kPa})$ \\
\hline 11,0 & 1 & 196 \\
14,9 & 2 & 196 \\
354,2 & 89 & 118 \\
358,1 & 90 & 118 \\
490,7 & 124 & 78,5 \\
494,6 & 125 & 78,5 \\
\hline
\end{tabular}

TUCCI (1993) apresenta metodologia para organizar classes de eventos, conforme sua magnitude, e, posteriormente, a atribuição da freqüência dos eventos dentro de cada intervalo. Essa metodologia foi usada na confecção da Tabela 2, a qual permite fazer análise mais detalhada do comportamento dos intervalos de lâminas coletadas na área, em função do número de observações, freqüência acumulada e época. Por exemplo, no intervalo $6,80-8,30 \mathrm{~mm}$, a $50 \%$ da velocidade máxima do pivô, o número de observações na primeira, segunda e terceira épocas foram, respectivamente, $41 ; 25$ e 7 , e a freqüência acumulada $56 \%, 26 \%$ e $6 \%$, mostrando diminuição das lâminas coletadas com o avanço da estação seca. Situação semelhante ocorre no intervalo de 3,59 4,30 mm, a $100 \%$ da velocidade máxima do pivô. O número de observações para a primeira, segunda e terceira épocas foram $22 ; 7$ e 3, e a freqüência acumulada $23 \%, 9 \%$ e 3\%, respectivamente. A $100 \%$ de capacidade de rotação do pivô central, verificou-se, no intervalo de $2,50 \mathrm{~mm}$ a $3,00 \mathrm{~mm}$, que, na primeira época, os números de observações foram bem menores que os da terceira época, e a freqüência acumulada das lâminas coletadas foi maior, ou seja, $66 \%$ das lâminas foram maiores ou iguais a esse intervalo, e na terceira época apenas 57\%. As lâminas menores verificadas com o avanço da estação seca podem advir do aumento da velocidade do vento, que afetou a eficiência de aplicação, principalmente entre a primeira e a terceira épocas.

Com os dados de freqüência acumulada, em função das lâminas coletadas e épocas, visualiza-se tendência de diminuição das lâminas de água coletadas com o avanço da estação seca no decorrer do ano, a qual foi acompanhada por incremento na velocidade do vento.

Para melhor interpretação da frequiência com que as lâminas coletadas foram distribuídas ao longo do pivô e melhor compreensão do termo área adequadamente irrigada (AAI), foi definida a $\mathrm{L}_{90}$ como a lâmina mínima coletada em $90 \%$ dos coletores, e que representa $81 \%$ da área irrigada. Para o pivô, em sua velocidade máxima, a $\mathrm{L}_{90}$ coletada, na primeira, segunda e terceira épocas, foi $2,25 \mathrm{~mm}$, $2,03 \mathrm{~mm}$ e $1,82 \mathrm{~mm}$, respectivamente. Já a $50 \%$ da velocidade máxima de deslocamento do equipamento, as $\mathrm{L}_{90}$ foram $5,15 \mathrm{~mm}, 4,03 \mathrm{~mm}$ e $4,40 \mathrm{~mm}$, para primeira, segunda e terceira épocas, respectivamente. Essas são as menores lâminas que, respectivamente, caem em $81 \%$ da área irrigada.

Os valores de CUC, apresentados na Tabela 3, ficaram um pouco abaixo do que RAMOS \& MANTOVANI et al. (1994) consideram como bons (80 a 90\%), provavelmente devido ao déficit de pressão observado no final da linha lateral. Conseqüentemente, as eficiências de irrigação (Ei), quando 
associadas à eficiência de aplicação, foram inferiores ao valor que a literatura cita como normal para Ei nesses sistemas de irrigação, que é de $80 \%$.

TABELA 2. Intervalo de classe, intervalo médio, número de observações (N. obs.), freqüência (F) e frequiência acumulada (Fac) das lâminas médias observadas ao longo de quatro raios do pivô, em três épocas do ano, a 50\% e 100\% de sua velocidade máxima.

\begin{tabular}{|c|c|c|c|c|c|c|c|c|c|c|}
\hline \multirow{2}{*}{$\begin{array}{c}\text { Intervalo } \\
\text { de Classe (mm) }\end{array}$} & \multirow{2}{*}{$\begin{array}{l}\text { Intervalo Médio } \\
\text { (mm) }\end{array}$} & \multicolumn{3}{|c|}{12 e $18-5-2002$} & \multicolumn{3}{|c|}{27 e $28-7-2002$} & \multicolumn{3}{|c|}{28 e $29-9-2002$} \\
\hline & & N.obs. & $\mathrm{F}(\%)$ & Fac (\%) & N.obs. & $\mathrm{F}(\%)$ & Fac (\%) & N.obs. & $\mathrm{F}(\%)$ & Fac (\%) \\
\hline \multicolumn{11}{|c|}{$50 \%$} \\
\hline $15,10-18,50$ & 16,80 & 1 & 1 & 1 & 0 & 0 & 0 & 0 & 0 & 0 \\
\hline $12,40-15,10$ & 13,75 & 0 & 0 & 1 & 0 & 0 & 0 & 0 & 0 & 0 \\
\hline $10,10-12,40$ & 11,25 & 3 & 2 & 3 & 3 & 2 & 2 & 0 & 0 & 0 \\
\hline $8,30-10,10$ & 9,20 & 27 & 21 & 24 & 5 & 4 & 6 & 1 & 1 & 1 \\
\hline $6,80-8,30$ & 7,55 & 41 & 32 & 56 & 25 & 20 & 26 & 7 & 5 & 6 \\
\hline $5,60-6,80$ & 6,20 & 34 & 27 & 83 & 27 & 21 & 47 & 45 & 35 & 41 \\
\hline $4,60-5,60$ & 5,10 & 19 & 15 & 98 & 25 & 20 & 66 & 42 & 33 & 74 \\
\hline $3,70-4,60$ & 4,15 & 2 & 2 & 99 & 28 & 22 & 88 & 25 & 20 & 94 \\
\hline $3,10-3,70$ & 3,40 & 1 & 1 & 100 & 8 & 6 & 95 & 3 & 2 & 96 \\
\hline $2,50-3,10$ & 2,80 & & & & 7 & 5 & 100 & 5 & 4 & 100 \\
\hline \multicolumn{11}{|c|}{$100 \%$} \\
\hline $4,30-5,15$ & 4,73 & 8 & 6 & 6 & 4 & 3 & 3 & 1 & 1 & 1 \\
\hline $3,59-4,30$ & 3,95 & 22 & 17 & 23 & 7 & 5 & 9 & 3 & 2 & 3 \\
\hline $3,00-3,59$ & 3,05 & 28 & 22 & 45 & 21 & 16 & 25 & 18 & 14 & 17 \\
\hline $2,50-3,00$ & 2,50 & 27 & 21 & 66 & 30 & 23 & 48 & 51 & 40 & 57 \\
\hline $2,09-2,50$ & 2,30 & 28 & 22 & 88 & 38 & 30 & 78 & 22 & 17 & 74 \\
\hline $1,75-2,09$ & 1,92 & 9 & 7 & 95 & 20 & 16 & 94 & 17 & 13 & 88 \\
\hline $1,46-1,75$ & 1,61 & 5 & 4 & 99 & 6 & 5 & 98 & 11 & 9 & 96 \\
\hline $1,22-1,46$ & 1,34 & 1 & 1 & 100 & 1 & 1 & 99 & 4 & 3 & 99 \\
\hline $1,02-1,22$ & 1,12 & & & & 0 & 0 & 99 & 0 & 0 & 99 \\
\hline $0,85-1,02$ & 0,94 & & & & 1 & 1 & 100 & 1 & 1 & 100 \\
\hline
\end{tabular}

A análise de variância para a eficiência de aplicação de água (Ea), em função de época e velocidade de deslocamento do pivô, indicou efeito altamente significativo $(\mathrm{p}<0,01)$ para época. Com o objetivo de identificar quais épocas foram estatisticamente superiores, realizou-se o teste de Tukey $(\mathrm{p}<0,05)$, verificando-se que os valores médios das eficiências de aplicação das épocas 1 e $2(0,86$ e $0,91)$ não diferiram entre si, mas diferiram da época $3(\mathrm{Ea}=0,79)$.

Diferença entre épocas não traduz informação plausível para ser utilizada na prática e sim quais as variáveis climáticas que poderiam determinar tais diferenças. Por isso, elaborou-se um modelo estatístico de regressão múltipla, considerando, numa primeira tentativa, a eficiência de aplicação como variável dependente e temperatura do ar, umidade relativa e velocidade do vento como variáveis independentes. Verificou-se que a variável temperatura do ar não foi significativa, nem a $10 \%$ de probabilidade, provavelmente devido à pouca amplitude térmica entre elas, com exceção da primeira época em relação às demais (Tabela 3). Nova regressão sem essa variável foi testada e, nesse caso, a análise de variância da regressão mostrou haver $96,6 \%$ de probabilidade de que as diferenças na eficiência de aplicação sejam explicadas pelas variações na umidade relativa do ar e na velocidade do vento.

Os coeficientes de regressão das variáveis climáticas (Tabela 4) evidenciam que a velocidade do vento influenciou de forma mais significativa $(\mathrm{p}=0,008)$ do que a umidade relativa do ar $(\mathrm{p}=0,068)$, os valores da eficiência de aplicação. A umidade relativa do ar só foi significativa a $6,8 \%$ de 
probabilidade, contudo optou-se por aceitar esse nível de significância, mantendo essa variável no modelo estatístico, pois ajuda a explicar as diferenças observadas entre as três épocas. Assim, com os coeficientes de regressão e o respectivo intercepto, o modelo estatístico pode ser representado pela equação:

$$
\mathrm{Ea}=1,22-5,844 \times 10^{-2} \mathrm{Vv}-5,368 \times 10^{-3} \mathrm{UR}
$$

em que,

Ea - eficiência de aplicação;

Vv - velocidade média do vento $\left(\mathrm{m} \mathrm{s}^{-1}\right)$, e

UR - umidade relativa do ar, $\%$.

TABELA 3. Médias das temperaturas (T), das umidades relativas do ar (UR) e das velocidades do vento $(\mathrm{Vv})$ durante os testes realizados em três épocas do ano de 2002. Valores médios em quatro linhas radiais de coletores, para duas velocidades de rotação do pivô das lâminas de água (Lm), dos coeficientes de uniformidade de Christiansen (CUC), das eficiências de distribuição (Ed), de aplicação (Ea) e de irrigação Ei, para as respectivas épocas.

\begin{tabular}{cccccccccc}
\hline Velocidade (\%) & Épocas & $\mathrm{T}\left({ }^{\circ} \mathrm{C}\right)$ & $\mathrm{UR}(\%)$ & $\mathrm{Vv}\left(\mathrm{m} \mathrm{s}^{-1}\right)$ & $\mathrm{Lm}(\mathrm{mm})$ & $\mathrm{CUC}$ & $\mathrm{Ea}$ & $\mathrm{Ed}$ & $\mathrm{Ei}$ \\
\hline \multirow{2}{*}{100} & $1^{1^{\mathrm{a}}}$ & 26,7 & 51 & 2,03 & 2,75 & 0,75 & 0,84 & 0,74 & 0,62 \\
& $2^{2^{\underline{a}}}$ & 32,4 & 40 & 1,81 & 2,45 & 0,79 & 0,89 & 0,78 & 0,69 \\
& $3^{\mathrm{a}}$ & 34,8 & 40 & 3,57 & 2,32 & 0,78 & 0,80 & 0,77 & 0,62 \\
\hline \multirow{2}{*}{50} & $1^{1^{\underline{a}}}$ & 32,3 & 41 & 1,62 & 6,68 & 0,77 & 0,88 & 0,76 & 0,67 \\
& $2^{2^{\underline{a}}}$ & 33,7 & 41 & 1,87 & 5,10 & 0,77 & 0,93 & 0,76 & 0,71 \\
& $3^{\text {a }}$ & 33,7 & 47 & 3,10 & 4,40 & 0,81 & 0,78 & 0,80 & 0,62 \\
\hline Média & & - & - & - & - & 0,78 & 0,85 & 0,77 & 0,66 \\
\hline
\end{tabular}

$1^{\underline{a}}$ época (12 e 18-5-2002), $2^{\mathrm{a}}$ época (27 e 27-7-2002) 3ª época (28 e 29-9-2002)

Com auxílio da eq.(5), foi elaborada a Figura 2, na qual podem ser comparados os dados observados de Ea com os ajustados, verificando que os mesmos tiveram bom ajuste, com $\mathrm{r}^{2}$ igual a 0,894 e sem diferença estatística entre os coeficientes encontrados e a reta $\mathrm{y}=\mathrm{x}$. Porém, observou-se pequena tendência da eq.(5), em superestimar os menores e subestimar os maiores valores de Ea (intercepto maior que zero e declividade menor que 1). Verificaram-se, também, maiores discrepâncias nos valores mais elevados de Ea.

TABELA 4. Teste T de Student dos coeficientes de regressão para os parâmetros climáticos estudados.

\begin{tabular}{lccc}
\hline Causa de Variação & Coeficiente de Regressão & Valor T (Student) & Probabilidade (p) \\
\hline Velocidade do vento & $-5,84410^{-2}$ & $-4,296$ & 0,008 \\
Umidade relativa & $-5,36810^{-3}$ & $-2,317$ & 0,068 \\
\hline
\end{tabular}

Intercepto $=1,22$; Coeficiente de determinação, $\mathrm{r}^{2}=0,894$ 


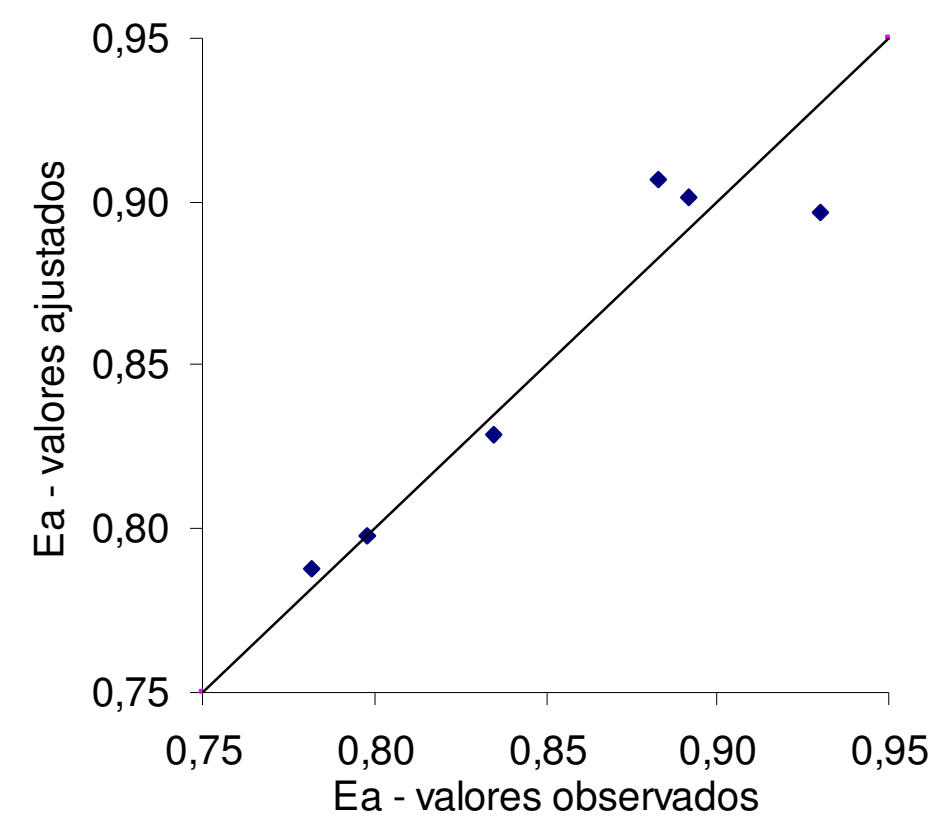

FIGURA 2. Valores ajustados por meio da eq.(5) versus valores observados da eficiência de aplicação de água média do pivô central.

\section{CONCLUSÕES}

Devido à insuficiência de pressurização promovida pela estação de bombeamento do pivô, o sistema avaliado apresentou, no final da linha lateral, pressão menor que a de projeto e, como conseqüência, a lâmina de água aplicada ficou, nesse trecho, abaixo da média.

As eficiências de irrigação (Ei) foram menores do que a considerada como aceitável na literatura especializada ( $80 \%)$.

As maiores lâminas coletadas têm freqüência acumulada reduzida com o avanço da estação seca ao longo do ano.

A velocidade do vento influenciou de forma mais significativa do que a umidade relativa do ar no valor da eficiência de aplicação de água pelo pivô.

\section{REFERÊNCIAS}

ASSIS, L.L. de; CASTRO, P.T. Avaliação de sistema de irrigação por pivô central. Engenharia Rural, Piracicaba, v.4, n. único, p.75-88, jul./dez., 1993.

BARREIRAS, Capital do Oeste da Bahia. Assessoria de Comunicação da Prefeitura Municipal de Barreiras. Salvador: Casa da Comunicação, 2000. 59 p.

BERNARDO, S. Manual de irrigação. 6. ed. Viçosa: Imprensa Universitária, 1995. 657 p.

CAINELLI, V.H.; ROBAIANA, A.D.; CARLESSO, R.; DOTTO, C.R.D. Desempenho e uniformidade da distribuição de água de um pivô central. Ciência Rural, Santa Maria, v.27, n.4, p.3540, 1997.

CEMIG - Companhia Energética de Minas Gerais. Estudo de otimização energética, setor de irrigação pivô central. Belo Horizonte, 1993. 22 p.

CHRISTOFIDIS, D. Irrigação, a fronteira hídrica na produção de alimentos. ITEM - Irrigação e Tecnologia Moderna, Brasília, n.54, p.46-55, 2002. 
FOLEGATTI, M.V.; PESSOA, P.C.S.; PAZ, V.P.S. Avaliação do desempenho de um pivô central de grande porte e baixa pressão. Scientia Agricola, Piracicaba, v.55, n.1, p.119-27, 1998.

FURUKAWA, M.C.; BERNARDO, S.; SOARES, A.A.; RAMOS, M.M. Avaliação da irrigação por pivô central na região de Rio Verde - GO. Ceres, Viçosa, v.41, n.233, p.36-49, 1994.

HEINEMANN, A.B.; FRIZZONE, J.A.; PINTO, J.M.; FEITOSA FILHO, J.C. Influência da altura do emissor na uniformidade de distribuição da água de um sistema tipo pivô central. Pesquisa Agropecuária Brasileira, Brasília, v.33, n.9, p.1487-91, 1998.

KELLER, J.; BLIESNER, R.D. Sprinkler and trickle irrigation. New York: Van Nostrand Reinhold, 1990. $652 \mathrm{p}$.

KLAR, E.A.; SANTANA, R. de C.; DUROHA, C. Evaluation center pivot systems using new and old sprays and pressure regulators. Irriga, Botucatu, v.6, n.1, p.70-7, 2001.

RAMOS, M.M.; MANTOVANI, E.C. Sistemas de irrigação e seus componentes. In: COSTA, E.F. da; VIEIRA, R.F.; VIANA, P.A. (Ed.). Quimigação: aplicação de produtos químicos e biológicos via irrigação. Brasília: EMBRAPA-CNPMS-SPI, 1994. p.41-84.

RESENDE, R.; FRIZZONE, J.A.; BOTREL, T.A. Desempenho de um sistema de irrigação pivô central quanto à uniformidade de distribuição de água abaixo e acima da superfície do solo.

Engenharia na Agricultura, Viçosa, v.2, n.19, p.1-7, 1993. (Série Irrigação e Drenagem)

RESENDE, R.; FRIZZONE, J.A.; FREITAS, P.S.L. de. Eficiência de irrigação utilizando pivô central. Unimar, Maringá, v.18, n.3, p.523-36, 1996.

TUCCI, C.E.M. Hidrologia, ciência e aplicação. 2. ed. Porto Alegre: Editora da Universidade do Rio Grande do Sul, 1993. 943 p. 